\title{
DIRECTIONS FOR IMPROVING THE PLANNING OF THE SUPPLY WITH CLOTHES, SHOES AND EQUIPMENT IN THE BULGARIAN ARMY
}

\author{
Daniel MANOLOV \\ "Vasil Levski" National Military University, Veliko Tarnovo, Bulgaria \\ didosm@abv.bg
}

\begin{abstract}
This paper presents ways of improving the planning of the supply of clothing, footwear and equipment in the following areas: priority purchase, terms of planning, output planning, planning of stocks and others. The main objective is to establish a methodology for planning the supply of clothing, footwear and equipment. All areas for improvement are consistent and identified in a resource-limited environment and dictated by the ability of the planning system to supply the Bulgarian Army. The paper also presents the option to use the ABC analysis to structure the planned activities of individual groups of property.
\end{abstract}

Keywords: planning, supply, Bulgarian Army

Planning is an essential part of ensuring normal life in military formations of the Bulgarian Army. The process of determining needs is tough, responsible and requires absolute commitment, so the working groups need to resolve a number of problems. One of the main problems is that the commands of the formations are not aware of the forthcoming reforms in the structures managed by them, which leads to inaccurate planning subsequent accumulation or serious shortage of material resources.

Another problem is the lack of accurate methodology for determining the needs of various clothing, footwear and equipment. The existing orders, directions, instructions and other guidance documents are numerous and they have already been amended a lot so far. Some of them were long time ago and are even contradictory, as they indicate different deadlines for implementation, which tremendously hinder the planning of the working groups. It turns out that it is extremely difficult to cover such a large set of documents, bearing in mind that small and medium-sized military formations even lack them. Due to these circumstances, it is imperative that scientific methodology and practical grounds be developed with a precise and realistic timetable, with uniform and comprehensive sample applications, requests, planning and other documents. The annual provision for the formations of the Bulgarian armed forces in peacetime with the necessary clothing, footwear and equipment is done by determining the needs of their existing standards for security. Full, correct and timely determination of needs is one of the guarantees of rhythm in sourcing and execution of the provision of clothing, footwear and equipment. The existing system of provision in the Bulgarian army allows military units, respectively their commanders to determine the need for clothing, footwear and equipment, and to declare before their insurance authority. The accuracy parameters of the request and the timely 
movement and allows the providing authority to draw an objectively real tangible plan in proportion to the needs of the Bulgarian army of clothing, footwear and equipment. It also provides details of the providing authority for contracts with production companies and firms.

The output data that logistic bodies use in the planning of the need for clothes, apparel and equipment are

- instructions of the Central Provision Authority on planning of clothing, footwear and equipment that are annual;

- standards to provide servicemen with clothing, footwear and equipment announced a ministerial order;

- the number of staff by category of servicemen;

- the number of civilian employers, who are entitled to clothing;

- existing stocks of clothing, footwear and equipment in military formations at the beginning of the year;

- The number of reservists to be called for retraining during the year and the duration of their retraining;

- The amount of equipment, the number of machines and facilities serving the provision of clothing, footwear and equipment;

- The number of sentry premises and posts to guard the objects at the military formation;

- The number of medical personnel on duty at the military formation, etc.

Based on these inputs, and after their detailed processing, the next step is preparation of planning documents for the supply of clothing, apparel and equipment. In the process of planning every serviceman draws up their own request for the above property, which is in compliance with the effective legislation and the relevant guidelines. Then in the course of planning the personal orders of the military are summarized by units and structures. Pooled applications are forwarded to the next hierarchical logistic bodies at the higher operational and strategic management level. The ultimate goal is to generate a single financial tangible plan for logistics, as the stated needs of this type of property are reflected in the relevant paragraphs. With the presented procedure of planning and use of input data, it is easy to identify the first direction for improving the planning of the supply of clothing, footwear and equipment. It is expressed in the identification of priority purchases that are required in the process of application.

In this direction the $\mathrm{ABC}$ analysis can be successfully used. By using it, the items of material property can be stored based on the "yearly successes" resulting in the need for them. The annual success shows how many times the product is requested in the summarized annual request regardless of its value. For example, the items of group "A" have the greatest financial value of the the total demand, but with the lowest percentage of orders. Here the applications for these products may be mandatory in the total annual demand for clothing, footwear and equipment and to have fixed periods of time for their delivery so that they are not to take additional warehouse space. Planning of the group ' $A$ ' property is binding and it would enable the strategic planning authorities to make an early market research for the property for which the total request is little in volume, but the items have a high unit price. This group, as its request is mandatory, brings amendments in the legislation, which is fundamental in the planning process. Planning documents and guidelines need to be amended so that they comply with the mandatory nature of the application of the property from group "A". [1]

In this regard Planning, Programming and Budget Directorate will be able to improve the its function to:

- coordinates the processes of mid- and short-term planning of the defense at the ministry and in structures directly subordinate to the Minister and in the 
Bulgarian Army;

- organizes preparation, necessary updates and reports on the implementation of a financial plan for material and technical provision of the ministry. [2]

Another direction for improving the planning in the supply of clothing, footwear and equipment is the determination of the planning factors. Planning factors are usually expressed as coefficients, relations or duration. When we talk about planning factors in logistics, these are relationships between two or more variables, and particularly for clothing that can be, for example value / service life. In this example, we can determine the planning factor as numerical factor used in planning, defining quality connection between providing personnel and stated needs. Planning factors are based on experience or specific periods of time. They are a tool for planning and making assumptions.

Requirements for logistics planning factors:

- to help determine the amount and composition of assets, and hence the necessary financial means for their procurement;

- be flexible, influenced by respective needs;

- be realistic etc.

To fulfill their role, the planning factors should be tied to the provision of the necessary material resources. These actors should give us the possibility to develop a financial plan for material - technical support with the following key indicators:

- volume of material property - total, in groups and kinds in natural units;

- volume of material property - total, in groups and kinds, in value and by relevant paragraphs;

- delivery time;

- amount of supply;

- accurate qualitative characteristics of the material property subject to supply;
- persons responsible for each group /formations/ and types of material property;

- budget.

The development of the plan requires reporting of specific relevant factors, as it is estimated they will occur in the next time period.

The next step in the course of our planned work should be setting goals and strategy of supplying relevant material property groups planned.

Defining the objectives and strategy of supply covers all the important material property department nomenclatures. For each of the stated nomenclatures material property it is checked whether at its acquisition any functional objectives of supply management is reported..

The next step is refining the needs expressed in the plan by conducting an analysis of market conditions:

- establish market stability;

- correction of initially set annual needs based on the analysis.

Analysis of suppliers is key in the analysis of market conditions, as it reveals the weaknesses and problems in the execution of orders, and highlights new features and benefits.

Another direction for improving the planning of the supply of clothing, footwear and equipment is the use of simulation modeling. In terms of applications, each type of product is characterized by a probability of presence in the application. This data is determined on the basis of statistics on actual movement of the property. It is desirable that the period for accumulation of information is long enough, so that the results have statistical significance.

In general, planning process of defense and Armed Forces traditionally involves several approaches and depending on the key factors, they are known as:

- targeted approach /or planning Top Down/

- Bottom-up planning; 
- Scenarios based planning;

- Threat-based planning;

- Mission-based planning;

- hedging;

- technological approach;

- financial approach. [3]

Based on the capabilities of the different approaches to planning and taking into account the requirements of planning the supply of clothing, footwear and equipment it was concluded that the most adequate approach is the Bottom-up. Combining the use of the approach to planning Bottom-up distribution of wealth through "ABC analysis" in which each of the groups has a different significance in the global demand and the introduction of group binding of application would provide movement of some of the applications in unit. This would provide a shorter time of planning and strategic marketing research at the ministry for a longer period. In this connection, planning ahead is a precondition for risk management and prevent future hazardous events associated with incorrect specifications, lack of funds, etc.. Items of a financial plan for material and technical provision shall be distributed among experts from relevant fields. It should be determined the type of procedure for public procurement and the degree of competition necessary to obtain the best estimate at minimal risk and prepare a draft of tender documentation.

A market research of clothing, footwear and equipment is performed in accordance with the potential contractors of the contract. This complies with the requirements of military technical specification for the subject of application.

The marketing body in strategic management level use internal and external sources of information:

- database of the department,

- Compass marketing information system,

- prepares written requests to the companies on quality, assortment, pricing;

- prepares written requests to statistical and professional organizations issuing market newsletters, commercial network, Internet and other means.

The use of $A B C$ analysis for the distribution of clothing, shoes and equipment in regard with their importance in the overall request would create a prerequisite for prioritizing the abovementioned internal and external sources of information.

In conclusion, I think that the proposed ways for improving the planning of the supply of clothing, footwear and equipment in the Bulgarian army would improve coordination of activities planned at the tactical, operational and strategic management level. Since they are tailored to modern resource-limited environment planning. The presented areas should allow for drawing up rules for handling in the development of planning methodology of clothing, footwear and equipment for the Bulgarian Army.

\section{References}

[1] Y. Koraliev, Logistics supply, University of National and World Economy, (Sofia, 1998), pp. $22-26$

[2] N. Nichev, Theoretical foundations of military logistics - organization of logistical support, Vasil Levski National Military University, (Veliko Tarnovo, 2011), pp. 19-21

[3] H.Bartlet, G.Holman, T.Somes, The art of Strategy and Force Planinig, in Strategy and Force Planinig, $4^{\text {th }}$ ed. (Newport, 2004 ), pp. 17-33 